\title{
Emotional intensity predicts autobiographical memory experience
}

\author{
JENNIFER M. TALARICO, KEVIN S. LABAR, and DAVID C. RUBIN \\ Duke University, Durham, North Carolina
}

\begin{abstract}
College students generated autobiographical memories from distinct emotional categories that varied in valence (positive vs. negative) and intensity (high vs. low). They then rated various perceptual, cognitive, and emotional properties for each memory. The distribution of these emotional memories favored a vector model over a circumplex model. For memories of all specific emotions, intensity accounted for significantly more variance in autobiographical memory characteristics than did valence or age of the memory. In two additional experiments, we examined multiple memories of emotions of high intensity and positive or negative valence and of positive valence and high or low intensity. Intensity was a more consistent predictor of autobiographical memory properties than was valence or the age of the memory in these experiments as well. The general effects of emotion on autobiographical memory properties are due primarily to intensity differences in emotional experience, not to benefits or detriments associated with a specific valence.
\end{abstract}

Some of the earliest investigations have described emotional experience as comprising two dimensionsvalence and intensity (e.g., Duffy, 1934, 1941; Dunlap, 1932). Others have extended this model to emotional memory for images, facial expressions, language, and experiences (Bradley, Codispoti, Cuthbert, \& Lang, 2001; Osgood, 1966; Robinson, 1980; Russell, 1980). The interaction of these dimensions on memory accuracy, persistence, or quality have been addressed, but rarely in combination.

Bradley, Lang, and colleagues (Bradley et al., 2001; Bradley, Greenwald, Petry, \& Lang, 1992) have examined memory for emotional words and pictures, consistently describing a "boomerang shape" (Bradley et al., 2001 , p. 277) of independent lines for positive and negative emotions diverging with increasing intensity (see Figure 1, top panel). They argued that for all positive emotions, the degree of positivity and the degree of intensity are functionally equivalent and that for all negative emotions, the degree of negativity and the degree of intensity are functionally equivalent. One alternative view, derived from studies of emotional language and

Portions of this research were presented at the 15th Annual Meeting of the American Psychological Society (2003). The article was written in part when D.C.R. was a visiting professor at the Psychology Department, University of Aarhus. This work was supported by a National Defense Science and Engineering Graduate Fellowship (to J.M.T.), National Institutes of Health Grant RO1 DA14094 (to K.S.L.), and a NARSAD Young Investigator Award (to K.S.L.). We thank Kevin Weinfurt for his statistical suggestions and Daniel G. Dillon and Daniel L. Greenberg for their comments on the project and the manuscript. Correspondence concerning this article should be addressed to J. M. Talarico, Department of Psychological and Brain Sciences, Duke University, Box 90086, Durham, NC 27708 (e-mail: jenrico@psych.duke.edu). supported by Russell and colleagues (Russell, 1980; Russell \& Carroll, 1999), is that valence is a bipolar dimension bisected by intensity. Emotions are then distributed in a circle, or circumplex, around a neutral valence point and moderate intensity (see Figure 1, bottom panel). One aim of the present study is to determine whether either of these patterns will emerge for autobiographical memories.

Multiple studies have extended the general dimensional approach of emotion to emotional memory. There is inconsistent evidence for valence effects in the episodic and autobiographical memory literature. Studies of valenced words and pictures have shown an advantage for the pleasant over the unpleasant (e.g., Anisfeld \& Lambert, 1966; Carter, 1936; Carter, Jones, \& Shock, 1934; Stagner, 1933). Diary studies often have shown enhanced recall for positive events (Linton, 1975; Wagenaar, 1986; White, 1982, 2002). Test-retest studies have shown that a greater number of pleasant events are initially reported and that a greater proportion of these are later recalled (e.g., Meltzer, 1930; O'Kelly \& Steckle, 1940). Berntsen (1996) found that participants had a greater number of pleasant than unpleasant involuntary autobiographical memories. Finally, Rubin and Berntsen (2003) found that requests for memories of extremely positive events produced memories that were older than those for extremely negative events in older adults, although the reverse happened in college-age respondents (Berntsen \& Rubin, 2002).

However, there is contradictory evidence for an advantage for the unpleasant over the pleasant for words, sentences (Ortony, Turner, \& Antos, 1983), and pictures (Bradley et al., 2001), especially during self-referential encoding (Banaji \& Hardin, 1994). A memory bias for negative events over positive events is also often pre- 

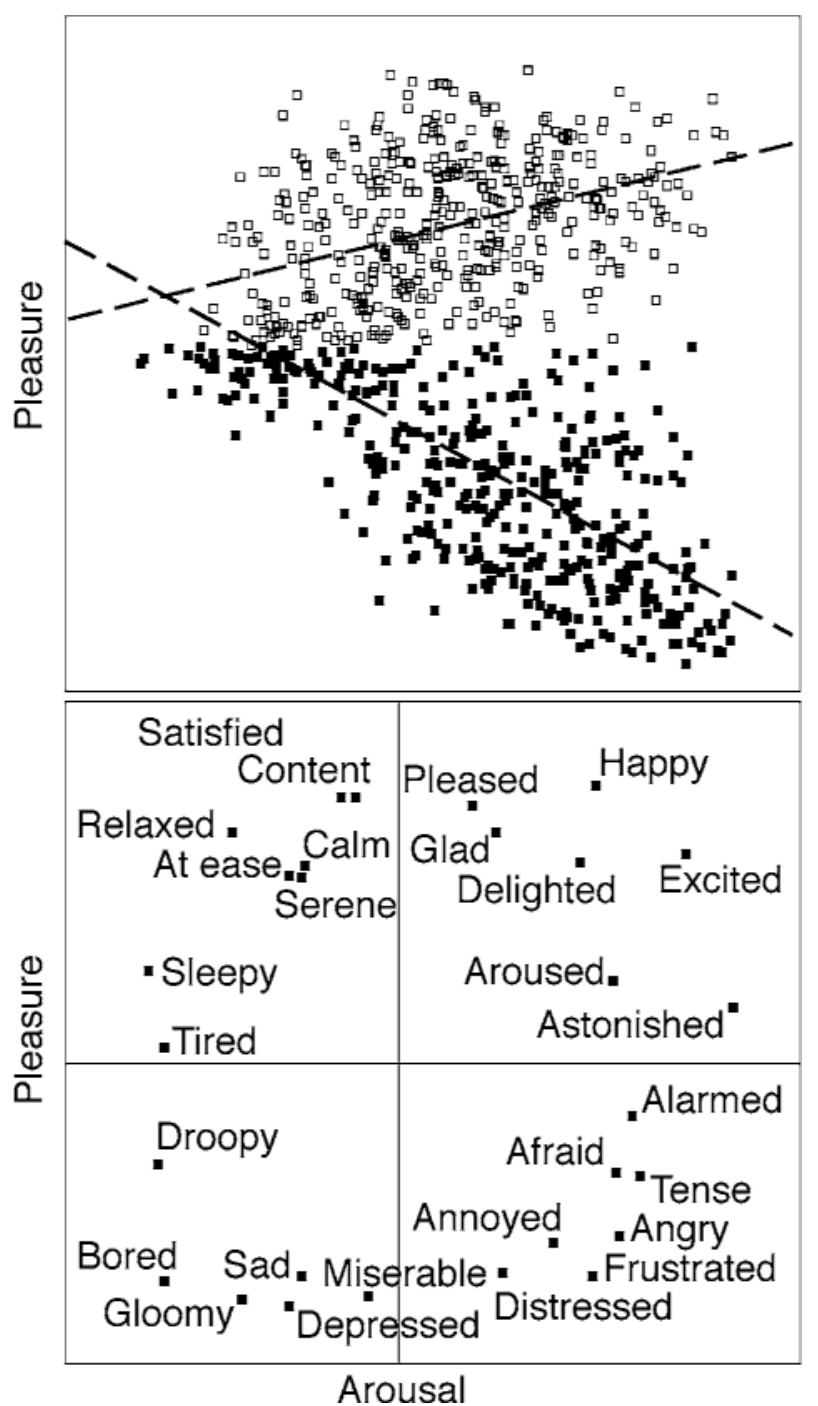

Figure 1. Prototypical examples of the vector (top panel) and circumplex (bottom panel) models. The top panel shows mean arousal and pleasure ratings of pictures from the International Affective Picture System (Lang, Bradley, \& Cuthbert, 1999). The bottom panel shows unidimensional scaling of 28 affect words on pleasure-displeasure and degree of arousal (Russell, 1980).

sented in trauma, eyewitness, and flashbulb memory research (e.g., Brown \& Kulik, 1977; Christianson, 1992a, 1992b; Tromp, Koss, Figueredo, \& Tharan, 1995).

Yet much of the evidence for an unpleasantness bias comes from comparisons of arousing negative stimuli with neutral stimuli (e.g., Banaji \& Hardin, 1994; Bradley et al., 2001; Carter, 1936), therefore providing equal support for an intensity bias. The findings of trauma, eyewitness, and flashbulb memory research are similarly limited. When direct comparisons are made, they are usually between a highly intense, negative target and an emotionally neutral item. In a recent review of the literature supporting an unpleasantness bias, Baumeister, Bratslavsky, Finkenauer, and Vohs (2001) concluded that such evidence "coexists with a tendency for individuals to recall positive information" (p. 344), concluding that within the memory literature, valence "does not appear to be the dominant force" (p. 344). Intensity findings are more consistent and, furthermore, can account for many of the valence contradictions. Waters and Leeper (1936) were the first to include subject-rated intensity in their study of emotional effects on memory and concluded that intensity was positively related to retention, whereas valence was unrelated. Holmes (1970) systematically investigated the interaction between valence and intensity and found that recall was greater for pleasant events than for unpleasant events and that memories for unpleasant events decreased in intensity more quickly than did memories for pleasant events. Holmes concluded that intensity more accurately predicted the recall differences that were evidenced as a pleasantness bias. This replicated and extended the earlier findings of Cason (1932) and Barlow (1955), who also found the intensity of unpleasant memories to fade more quickly than that of pleasant memories. Thompson (1985) found no effect of valence on forgetting rates of personal events, but a strong effect of emotional intensity. Similarly, Walker, Vogl, and Thompson (1997) found that the intensity of unpleasant events fades more quickly over time than that of pleasant events and that, because intensity predicts long-term recall, pleasant events are remembered better than unpleasant events in long-term, but not necessarily in short-term, recall.

\section{Remembering Versus Memory}

Previous investigators have concentrated on the contents and retention of memory for emotional events. These studies lacked consideration of the phenomenological properties of the memory and the process of remembering. However, there have been some studies in which the individual properties of autobiographical memory have been examined in association with emotional valence and/or intensity. These studies have investigated belief/confidence in the memory's accuracy, vividness, field/observer perspective, narrative coherence, whether the memory is specific or general, rehearsal, similarity of emotion and intensity at the time of the event and as it is remembered, and/or visceral reactions to the memory, in addition to the mere presence or absence of an emotional event in memory.

Belief/confidence. Individuals are usually confident in their memory; they believe that the way they remember an event is the way that it actually occurred. However, they are also usually willing to admit that memory is fallible and that sometimes their memory may not be an accurate reflection of reality. Studies of false memories (e.g., Loftus, Donders, Hoffman, \& Schooler, 1989) and disputed memories (Sheen, Kemp, \& Rubin, 2001) have identified several characteristics that influence confidence in one's memory but have not focused on emotion per se. Some emotional memory researchers have addressed this issue, although not in depth. Gordon's (1928) participants said that they were "very certain" of the accuracy of negative memories more often than they did for positive memories. This is consistent with find- 
ings from the flashbulb memory literature that have suggested that memories of highly intense, negative events are held with more confidence than are memories of neutral events that are equally old (Brown \& Kulik, 1977; Neisser \& Harsch, 1992; Talarico \& Rubin, 2003).

Vividness. Vividness, often defined as the amount of perceptual or sensory detail, has been the autobiographical memory property studied most in emotional memories. A strong correlation between memory vividness and emotionality is a common finding (Conway \& Bekerian, 1988; Rubin \& Kozin, 1984; Wagenaar, 1986; R. T. White, 1982). In these studies, emotionality is not defined in terms of valence or intensity, but the pattern of results is more consistent with previous findings for intensity. Reisberg, Heuer, McLean, and O'Shaughnessy (1988) found emotional intensity to be highly correlated with memory vividness. Within involuntary autobiographical memories, Berntsen (2001) found that traumatic memories and memories for peak positive events are more vivid than less intense memories. For valence, some studies have shown that positive memories are more vivid than negative memories (Destun \& Kuiper, 1999; Larsen, 1998; Raspotnig, 1997). In these studies, the degree of intensity was not measured, and none include a neutral memory for comparison. D'Argembeau, Comblain, and Van Der Linder (2003) found that positive memories were more vivid than negative and neutral memories, which were equally vivid. On the contrary, Bluck and $\mathrm{Li}$ (2001) found that anger and sadness were correlated with vividness but that happiness and surprise were not. They also found negative emotionality in general to be related to vividness. However, all the memories in this study were of the same emotional event and were not compared with a neutral control event. Finally, Hayes, Conway, and Morris (1992) found no differences in vividness between positive and negative memories. Therefore, it seems that intensity is the most reliable predictor of memory vividness, but the current evidence is not conclusive.

Field/observer. Whether one sees the memory through one's own eyes (field) or through the eyes of an outside observer (observer) is a relatively recent area of interest within autobiographical memory research. D'Argembeau et al. (2003) found that emotional memories (regardless of valence) were more likely to be seen through one's own eyes (a field perspective) than were neutral memories. This is consistent with earlier findings of Nigro and Neisser (1983) and Strongman and Kemp (1991). In contrast, Robinson and Swanson (1993) found that high- and low-intensity memories were equally likely to be encoded from an observer's perspective but that switching from a field view to an observer's perspective led to a decrease in the emotional intensity of the memory. Talarico and Rubin (2003) found that flashbulb memories (which were more negative and of higher intensity than everyday memories) were not more likely to change from an observer to a field perspective over time, although everyday memories were. There are no studies in which intensity has been examined separately from valence, and the relationship between valence and perspective is contradictory. Thus, the effects of emotion on memory perspective have yet to be definitively described.

Narrative coherence. Narrative coherence is defined as whether a memory is recalled as a unified coherent story, either in words or in images, rather than as fragmentary isolated details. The latter has been characterized as a hallmark of posttraumatic stress disorder (especially flashbacks and recurring memories). Van der Kolk and Fisler (1995) found that memories for traumatic or traumatic-like events were less likely to be recalled in a coherent narrative form, although others have not (Berntsen, Willert, \& Rubin, 2003; Rubin, Feldman, \& Beckham, 2004; Talarico \& Rubin, 2003).

Specific/general. Although we often merge many similar or related events into a common memory representation of that type of event (Neisser, 1981), such memories are usually still unique to our own lives. Schema-based memories of common events are not unique to any one participant (Williams, 1995). Often this distinction is operationalized as the number of specific contextual details present in a memory account that could not be generated from abstract world knowledge. D'Argembeau et al. (2003) found that positive memories included more contextual details than did negative or neutral memories. Destun and Kuiper (1999) also found more context in positive memories than in negative ones.

Rehearsal. A large number of studies have shown that high-intensity memories were thought or talked about (either explicitly or involuntarily) more often than were lowintensity memories (Berntsen, 1996, 1998; Cason, 1932; Waters \& Leeper, 1936). However, Guy and Cahill (1999) argued that rehearsal alone cannot account for recall differences between high- and low-intensity memories. Valence effects in rehearsal are less consistent. Menzies (1935) reported no difference in rehearsal rates between positive and negative memories, as did Berntsen (1998). Bluck and Li (2001), in examining specific emotional reactions, reported that feeling happy was correlated with rehearsal but that feeling angry, sad, or surprised was not.

Same emotion/intensity. Memories of past emotional experiences are often used to recreate current emotional states (Conway, 1990; Conway \& Bekerian, 1987a; Schwartz, Weinberger, \& Singer, 1981; Washburn, Deyo, \& Marks, 1924; Washburn, Field, \& Wolf, 1923; Washburn, Giang, Ives, \& Pollock, 1925). Stability in emotional tone between memory reports for both older and younger adults was reported by Anderson, Cohen, and Taylor (2000). Washburn et al. (1923) found that memories of joy were remembered with the same intensity more often than were memories of anger or fear. However, Levine (1997) reported a systematic bias in reporting past emotional intensity to be more like current emotional intensity, as assessed by comparing self-reports at initial recall with those at delay.

Visceral. Rubin et al. (2004) and Talarico and Rubin (2003) found that visceral and cognitive aspects of emotion can act independently, with visceral reactions being more strongly correlated with posttraumatic stress disorder symptom severity. Berntsen (2001) found that in- 
Table 1

Mean Values (With Standard Deviations) for Positive and Negative Emotions

\begin{tabular}{lccccccc}
\hline & \multicolumn{2}{c}{ Positive } & & \multicolumn{2}{c}{ Negative } & & By Emotion \\
\cline { 2 - 3 } & $M$ & $S D$ & & $M$ & $S D$ & & $\begin{array}{c}\text { By Participant } \\
t(70)\end{array}$ \\
\hline Recollection & 4.73 & 0.19 & & 4.48 & 0.33 & 2.04 & $2.82^{* *}$ \\
Remember/know & 5.73 & 0.16 & & 5.67 & 0.29 & 0.55 & 1.24 \\
Real/imagine & 6.28 & 0.08 & & 6.13 & 0.16 & $2.71^{*}$ & $3.12^{* *}$ \\
Vivid & 5.17 & 0.21 & & 5.06 & 0.28 & 0.97 & 1.82 \\
Field/observer & 5.48 & 0.16 & & 5.39 & 0.33 & 0.73 & 1.26 \\
In words & 3.16 & 0.22 & & 3.22 & 0.27 & -0.53 & -0.91 \\
Narrative & 4.52 & 0.20 & & 4.32 & 0.31 & 1.72 & $2.04^{*}$ \\
Specific & 5.52 & 0.22 & 5.60 & 0.38 & -0.59 & -1.92 \\
Rehearsal & 3.29 & 0.36 & 3.18 & 0.54 & 0.54 & 1.57 \\
Same emotion & 4.76 & 0.33 & 4.58 & 0.43 & 1.05 & 1.84 \\
Same intensity & 3.93 & 0.29 & & 3.78 & 0.56 & 0.73 & $3.15^{* *}$ \\
Visceral & 1.76 & 0.35 & & 2.24 & 0.46 & $-2.59 *$ & $-7.25^{* *}$ \\
Intensity & 4.02 & 0.34 & 4.03 & 0.66 & -0.07 & -0.46 \\
Valence & 6.12 & 0.57 & & 2.08 & 0.40 & $19.13^{* *}$ & $39.91^{* *}$ \\
Memory age & 2.30 & 0.45 & 3.20 & 1.21 & $-2.35^{*}$ & $-4.87^{* *}$ \\
\hline
\end{tabular}

Note-Positive emotions were proud, happy, excited, satisfied, calm, amused, surprised, relieved, and anxious-positive. Negative emotions were ashamed, bored, disappointed, embarrassed, afraid, guilty, lonely, annoyed, sad, disgusted, angry, and anxious-negative. Due to inequality of variance in real/imagine and memory age, Satterthwaite $t$ values are reported. $* p<.05$. $* * p<.01$.

voluntary memories of traumatic and of peak positive events had a greater influence on current emotion and were more visceral than were less intense memories. Analyzing the independent contribution of each cognitive emotional dimension to visceral reactions may prove equally informative. Current physical reactions to past emotional events have been investigated for a small number of emotional experiences. Washburn et al. (1923) found that joyful memories included more "bodily manifestations" than did fearful or angry memories (p. 103). Strongman and Kemp (1991) found that negative emotional memories were more likely to accompany physical reactions, with anger being associated with behavioral reactions and fear being associated with physiological reactions. Schwartz et al. (1981) found that cardiac response was insufficient to reliably discriminate specific emotions but did find reliable diastolic, systolic, and heart rate changes while happy, angry, fearful, and sad memories were remembered.

\section{Remembering Emotional Events}

In sum, previous literature has shown inconsistent effects of emotion on memory. The relationship between intensity, valence, and autobiographical memory is incomplete and, in some cases, contradictory. Some properties of autobiographical memory, such as recollection, whether the memory is remembered or the individual simply knows it occurred, and linguistic properties that have been studied in the context of normative autobiographical memory research have not been systematically investigated for emotional memories. The aim of the present study is to provide a more detailed picture of the phenomenological properties of autobiographical memory and how they are affected by emotional valence and intensity.

\section{EXPERIMENT 1}

\section{Method}

Participants. Duke University undergraduates $(N=71,22$ of whom were males) participated for course credit in small groups.

Procedure. After providing informed consent, the participants were given a definition of autobiographical memory as "a memory for an event from your personal past. It is usually a specific, datable event that you were personally involved in. It is usually a snapshot of a specific scene rather than a film about a period of time or an extended event. There is usually a plot, a setting, and characters. However, not all of these characteristics must be present in each individual memory. Memories can be from any time in your life from early childhood up to what you did right before coming here today. Autobiographical memories are not facts and they are not about events that will happen in the future."

They were then given a description of the task and were asked to generate memories for times when they felt "especially

for 20 distinct emotions (amused, angry, annoyed, anxious, ashamed, bored, calm, disappointed, disgusted, embarrassed, excited, afraid, guilty, happy, lonely, proud, relieved, sad, satisfied, and surprised). ${ }^{1}$ There were four different orders of emotions, randomized during testing, with each following these rules: no more than 2 consecutive negative emotions, always ending with 2 positive emotions, and varied emotional intensity. These rules were instituted to prevent inadvertent mood induction. The participants were told that they could skip any questions they did not feel comfortable completing. In addition, if, for whatever reason, the participants had not finished after $55 \mathrm{~min}$ had passed, they were instructed to skip ahead to the last two emotion questions; this was done to prevent anyone from leaving the testing room in a negative mood. Only 7 participants left more than one emotion question blank, and each of these completed at least 15 of the 20 emotion questions. After each participant had finished, he or she was given a written debriefing form and contact information for the experimenter.

For each emotion presented, the participants wrote a brief description of the memory event and then answered various rating scale questions about the properties of the memory. These questions were taken from the Autobiographical Memory Questionnaire (AMQ), which was derived from various existing autobiographical 
Table 2

Mean Values (With Standard Deviations) for High- and Low-Intensity Emotions

\begin{tabular}{|c|c|c|c|c|c|c|}
\hline & \multicolumn{2}{|c|}{ High Intensity } & \multicolumn{2}{|c|}{ Low Intensity } & \multirow{2}{*}{$\frac{\text { By Emotion }}{t(19)}$} & \multirow{2}{*}{$\frac{\text { By Participant }}{t(70)}$} \\
\hline & $M$ & $S D$ & $M$ & $S D$ & & \\
\hline Recollection & 4.70 & 0.27 & 4.46 & 0.29 & 1.91 & $3.24 * *$ \\
\hline Remember/know & 5.82 & 0.17 & 5.57 & 0.24 & $2.86^{*}$ & $3.40 * *$ \\
\hline Real/imagine & 6.23 & 0.14 & 6.15 & 0.15 & 1.31 & 1.19 \\
\hline Vivid & 5.19 & 0.22 & 5.02 & 0.26 & 1.68 & $3.15 * *$ \\
\hline Field/observer & 5.51 & 0.23 & 5.34 & 0.29 & 1.52 & 1.34 \\
\hline In words & 3.27 & 0.20 & 3.11 & 0.27 & 1.50 & $2.66^{* *}$ \\
\hline Narrative & 4.53 & 0.27 & 4.27 & 0.24 & $2.33 *$ & $3.37 * *$ \\
\hline Specific & 5.70 & 0.32 & 5.41 & 0.25 & $2.28 *$ & $3.69 * *$ \\
\hline Rehearsal & 3.49 & 0.37 & 2.94 & 0.40 & $3.30 * *$ & $9.87 * *$ \\
\hline Same emotion & 4.78 & 0.34 & 4.52 & 0.43 & 1.56 & $6.89 * *$ \\
\hline Same intensity & 4.05 & 0.42 & 3.62 & 0.41 & $2.38 *$ & $4.71 * *$ \\
\hline Visceral & 2.28 & 0.35 & 1.76 & 0.46 & $2.96^{* *}$ & $7.71^{* *}$ \\
\hline Intensity & 4.36 & 0.31 & 3.65 & 0.48 & $4.08 * *$ & $11.71 * *$ \\
\hline Valence & 3.44 & 2.28 & 4.22 & 1.92 & -0.84 & $-13.85^{* *}$ \\
\hline Memory age & 2.74 & 0.83 & 2.90 & 1.29 & -0.34 & -0.49 \\
\hline
\end{tabular}

Note-High-intensity emotions were lonely, disgusted, disappointed, proud, ashamed, excited, happy, sad, angry, anxious-positive, and anxious-negative. Low-intensity emotions were bored, calm, embarrassed, afraid, guilty, amused, annoyed, relieved, satisfied, and surprised. $* p<.05$. $\quad * * p<.01$.

and general memory theories and is sensitive to the conscious experience of remembering (Rubin, Burt, \& Fifield, 2003; Rubin, Schrauf, \& Greenberg, 2003; Sheen et al., 2001). This allows us to study not just global variations due to emotion, but also differential effects on specific properties of autobiographical memory. The complete text of the questionnaire used here is given in the Appendix. Of the AMQ questions, 14 were specifically directed at autobiographical memory properties (recollection, belief in the memory's accuracy, vividness, linguistic/narrative form, rehearsal, and age). A sense of recollection is a defining property of autobiographical memory (Brewer, 1986, 1995) and was assessed here with four variables. The first was created by averaging participant responses to ratings of reliving and of traveling back to the time when it happened. Another metacognitive judgment of phenomenology was whether they remembered the event or if they just knew that the event had taken place. The participants were also asked to rate each memory on a scale from $100 \%$ real to $100 \%$ imagined, to assess belief in the memory's accuracy. Vividness, another hallmark of autobiographical memory (Conway \& Bekerian, 1987b; Rubin \& Kozin, 1984), was assessed here with the average of three imagery questions: visual, spatial, and auditory. There was also 1 question aimed at perspective in the memory: whether one saw the event through his/her own eyes or the eyes of an outside observer. A linguistic component was assessed with only one question: Did the memory come in words? The question regarding whether the memory came in pieces was reverse coded and averaged with responses to whether the memory came as a coherent story, to determine narrative form. There was one question referring to the type of event recalled, which was whether the memory was of an event specific to the participant's own life. Rehearsal of memory content was assessed with the average of two questions: one aimed at voluntary remembering (how often did he/she think or talk about the event?) and one at involuntary remembering (how often did the memory come "out of the blue"?). The participant also reported his or her age at the time of the memory, which was then subtracted from the participant's current age to obtain the memory age.

The other eight AMQ questions were directed at characterizing emotional variables. Intensity was assessed with an individual question on emotional intensity. The vector model (Bradley et al., 2001; Bradley et al., 1992; Lang, 1995) requires individual scales for positive and negative valence. The circumplex model assumes that va- lence is a bipolar dimension with positive and negative anchors (Russell, 1980; Russell \& Carroll, 1999). We therefore included two questions, one each for positive and negative feelings. We then computed an overall valence scale from those measures [positive scale $+(8-$ negative $) / 2=$ valence]. There were also two questions used to assess the persistence of emotional experience-whether the emotions remembered were as strong as they had been when the event occurred and whether the same emotion was felt at remembering as when it occurred. Finally, we asked about the physical reactions associated with emotional experience, arriving at an average of three ratings of visceral responses (feeling an increased heart rate, feeling sweaty, and feeling tense).

All the variables were analyzed using multiple regressions. The independent variables were always intensity, valence, and memory age. With the age of the memory included as a predictor variable, retention differences between high- and low-intensity or positive and negative emotions could not be driving the overall effects of intensity or valence on autobiographical memory properties. The remaining variables were treated as dependent variables.

\section{Results and Discussion}

Order of presentation did not affect participant responses on any of the AMQ variables (autobiographical memory or emotion specific; $F<1$ for all). Therefore, all subsequent analyses were collapsed across groups. In preliminary data analysis, we noticed that although we intended anxious to be a negative emotion, the participants seemed to recall positive experiences, such as being anxious for a loved one's arrival or being anxious for an upcoming event, as well as negative experiences, such as being anxious about an exam result or anxious about starting in a new school. Therefore, we created a positiveanxious emotion and a negative-anxious emotion. In order to be in either category, one's score had to be above the median on one scale and below the median on the other. Twenty-seven participants were included in the anxiouspositive group, and 32 were included in the anxiousnegative group. The number of participants responding to 
Table 3

Memory Age, Intensity, and Valence Regressed on Each of the Autobiographical Memory Properties Over All Emotions

\begin{tabular}{|c|c|c|c|c|c|c|c|}
\hline & \multicolumn{4}{|c|}{ Standardized $\beta$} & \multicolumn{3}{|c|}{$r^{2} \mathrm{Y}(\mathrm{X})$} \\
\hline & $R^{2}$ & Age & Intensity & Valence & Age & Intensity & Valence \\
\hline Recollection & .81 & -.17 & $.82 * *$ & $.35 * *$ & .03 & .66 & .10 \\
\hline Remember/know & .70 & .01 & $.84 * *$ & .16 & .00 & .69 & .02 \\
\hline Real/imagine & .61 & $-.46^{*}$ & $.51 * *$ & .25 & .18 & .25 & .05 \\
\hline Vivid & .56 & .10 & $.73 * *$ & .30 & .01 & .52 & .08 \\
\hline Field/observer & .62 & $-.68 * *$ & $.45 * *$ & -.17 & .39 & .20 & .02 \\
\hline In words & .41 & -.25 & $.56^{* *}$ & -.22 & .05 & .31 & .04 \\
\hline Narrative & .68 & -.09 & $.78 * *$ & $.32 *$ & .01 & .59 & .08 \\
\hline Specific & .52 & .13 & $.68 * *$ & -.12 & .02 & .45 & .01 \\
\hline Rehearsal & .87 & -.01 & $.94 * *$ & .16 & .00 & .86 & .02 \\
\hline Same emotion & .70 & $-.45^{* *}$ & $.68 * *$ & .09 & .17 & .46 & .01 \\
\hline Same intensity & .79 & -.24 & $.85 * *$ & .10 & .05 & .70 & .01 \\
\hline Visceral & .76 & $.30 *$ & $.59 * *$ & $-.41 * *$ & .08 & .34 & .14 \\
\hline
\end{tabular}

each question for each of the other 19 emotions varied from 65 to 71 .

The main analyses in Experiment 1 were conducted using the 21 emotions as the units of analysis, rather than the 71 participants (see Clark, 1973, and Rubin, 1985, for discussions of this strategy). We did this in order to display each emotion as a separate point in the figure and the tables and because averaging over emotions is counter to theoretical perspectives that claim that every emotion, or at least every basic emotion, is unique (Ekman, 1992; Izard, 1992; Oatley \& Johnson-Laird, 1987). To ensure that any significant effects obtained were not a result of these emotions not being statistically independent, we also summarized more traditional analyses, using participants as the units. Furthermore, in Experiments 2 and 3, which analyzed multiple memories of the same emotion, we also included the results for which participants was used as the unit of analysis for each of those same individual emotions from Experiment 1.

Comparisons were computed between the groups of positive versus negative and high- versus low-intensity emotions. Tables 1 and 2 display differences between the groups. The first column of $t$ tests was calculated over the 21 emotions. Importantly, in this analysis, there was no significant difference between positive and negative emotions on intensity and no significant difference in valence between high- and low-intensity emotions. Overall, there were more significant differences between highand low-intensity emotions than between positive and negative emotions. The second column of $t$ tests was calculated by computing the difference between the average ratings of positive and negative or high- and lowintensity emotions for each participant. The same pattern was true with participants as the unit of analysis: There were still more and greater differences between intensities than between valences, especially within the autobiographical memory-specific properties.

The age of the memory, intensity, and valence were included as the independent variables in the multiple regression analyses, to determine which of these factors had the greatest influence on the phenomenological properties of the autobiographical memories. For each emotion, the average ratings across all participants were included. These 21 emotions were then included in the overall multiple regression model. Total $R^{2}$ values, standardized beta weights, and squared semi-partial correlations are shown in Table 3 for all memory properties for all emotions. Positive and negative valence could have produced different effects than our computed valence scale did, but in fact, if the memory age, intensity and only the positive scale or only the negative scale are included in the regression, none of the values included in Table 3 changes by more than .03 . Therefore, we include only the results of the analysis done with valence.

The age of the memory significantly predicted field/ observer perspective, consistent with previous findings that more recent memories are more likely to be seen through one's own eyes (Nigro \& Neisser, 1983). More recent memories were also more likely to be confidently held and were more likely to elicit the same emotion now as when the event had originally occurred. Interestingly, older memories were accompanied by greater visceral

Table 4

Number of Individual Emotions for Which Memory Age, Intensity, or Valence Was a Significant Predictor for Each Autobiographical Memory Property

\begin{tabular}{lccc}
\hline & Age & Intensity & Valence \\
\hline Recollection & 8 & 20 & 0 \\
Remember/know & 4 & 12 & 1 \\
Real/imagine & 11 & 6 & 5 \\
Vivid & 2 & 16 & 0 \\
Field/observer & 1 & 8 & 3 \\
In words & 0 & 14 & 2 \\
Narrative & 8 & 15 & 0 \\
Specific & 2 & 7 & 5 \\
Rehearsal & 0 & 17 & 0 \\
Same emotion & 6 & 21 & 1 \\
Same intensity & 4 & 21 & 1 \\
Visceral & 2 & 20 & 1 \\
\hline
\end{tabular}

Note-Maximum $=21$. 
reactions. More positive memories predicted a greater sense of recollection and more narrative but predicted less visceral reaction while the event was being remembered. However, the most striking result shown in Table 3 is that intensity significantly predicted every autobiographical memory property. With the exception of field/observer (for which memory age uniquely accounted for a greater proportion of the variance), at least one quarter of the variance for each property was uniquely accounted for by intensity alone, and the proportion accounted for by intensity was greater than that accounted for by either of the other two predictor variables.

These findings are generally consistent with analyses done with participants as the unit of analysis for each emotion individually (as is shown in Table 4). Here, with 21 emotions and an alpha of .05, one would expect, on the basis of chance alone, significant results for one emotion on each property, but the number of emotions for which intensity significantly predicts each property was much larger. In addition, intensity was a significant predictor for more emotions than was either of the other predictors for each property except real/imagine. Overall, intensity was a significant predictor of more autobiographical memory properties than was the age of the memory or valence in both the by-emotion and the byparticipant analyses.

Given this support for a dimensional approach to emotion and memory, the spatial configuration of these dimensions was examined next. The 21 emotions are plotted in Figure 2 as a function of their intensity and valence, averaged over participants. The vector model has been plotted for the International Affective Picture System (IAPS; Lang, Bradley, \& Cuthbert, 1999), other sets of emotional pictures (Bradley et al., 2001), and emotional language (Bradley \& Lang, 1999). However, personality states (Fisher, Heise, Bohrnstedt, \& Lucke, 1985), personality traits (Conte \& Plutchik, 1981), and emotional language (Russell, 1980) have all been plotted on the circumplex. We extended each of these models to autobiographical memory, as is shown in Figure 2.

The circumplex model has the origin located at the intersection of the gross means for intensity and valence, and its radius is set to the average distance from that point to the 21 emotions. Note that although we selected positive and negative emotions of varied intensity, there are areas that are underrepresented. The distance between each point and the origin was compared with the radius of the circle predicted by the mean values of all the emotions. None of the individual emotions was more than one standard deviation greater than this predicted radius. However, the emotions do not form a circle with varied radii but, instead, form clusters of emotions that are approximately equidistant from the origin. This pattern is more consistent with the vector model of emotion and emotional memory.

The axes for the vector model are determined by separate regression lines calculated for the positive emotions from the positive scale and for the negative emotions from the negative scale. Note that as predicted by the vector model, they intersect very near the midway point on the

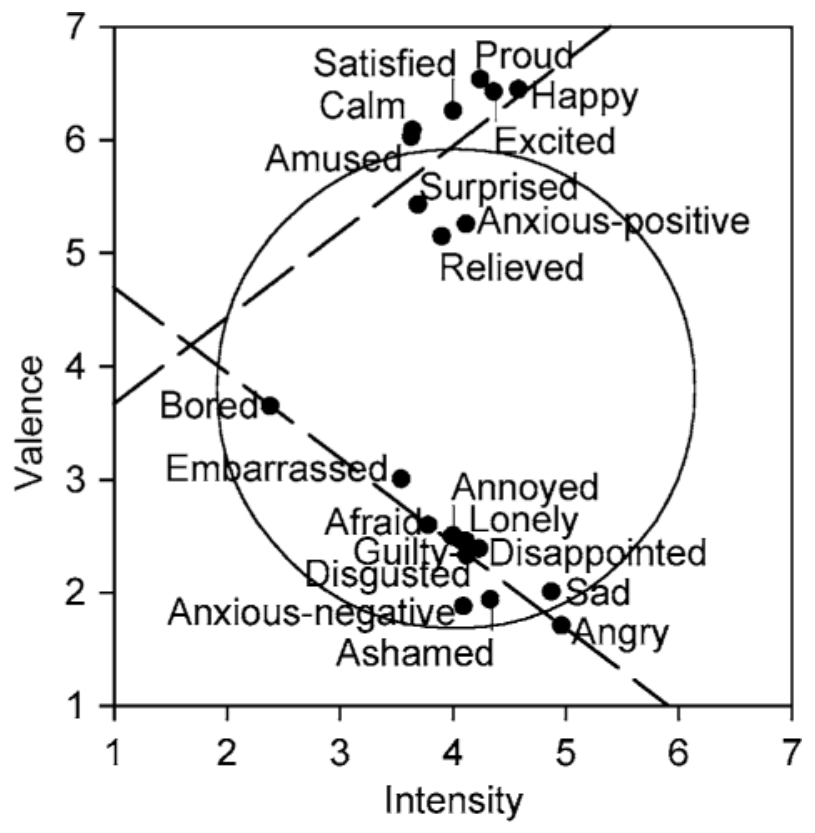

Figure 2. Plots of mean valence and intensity ratings across participants for the autobiographical memories from 21 distinct emotions. The circumplex is centered around mean intensity (4.03) and valence (3.81) ratings, with a radius of the average distance from that point to the 21 emotions (2.06). The vectors are independent regression lines for positive $\left(R^{2}=.22\right)$ and negative $\left(R^{2}=.86\right)$ emotions.

valence scale (4.00) and the lowest value on the intensity scale (1.00), even though there is no necessary statistical reason for this occur. The vector model qualitatively fits the data much better than does the circumplex model.

\section{EXPERIMENT 2}

Although Experiment 1 produced few differences that were due to emotional valence, this could be an artifact of the specific autobiographical memories the participants chose- that is, their "most angry" or "happiest" memory may be different than other exemplars in that category. Therefore, in Experiment 2, the participants generated multiple autobiographical memories from emotional categories of equal intensity but of opposite valence. We chose two basic emotions, happy and angry, because it was easy for the participants to generate multiple autobiographical memories from these categories. In Experiment 3 , we correspondingly compared emotions of equal valence but of opposite intensity.

\section{Method}

Participants. Duke University undergraduates $(N=78,38$ of whom were male and none of whom had participated in Experiment 1) participated for course credit.

Procedure. After providing informed consent, the participants were given the definition of autobiographical memory from Experiment 1 and a description of the task.

They then generated a list of 10 important people in their lives (e.g., friends, roommates, relatives, etc.). For each individual listed, 
the participants first provided their happiest memory with that individual and then their angriest memory involving that person. This order was chosen to prevent residual anger from memory generation from reducing the accessibility of happy memories. The person generation task was chosen to encourage the participants to select memories of varied experiences and to avoid any "quintessential" experiences, as were likely provided in Experiment 1. In addition, the participants were likely to engage in similar experiences with a given individual, increasing the similarity of nonemotional content across memories.

For each memory generated, the participant completed the same questionnaire as that used in Experiment 1. The last memory cue, which was not analyzed, asked for the participant's happiest memory overall, regardless of the individuals involved; this was done to minimize any mood induction. After each participant had finished, he or she was given a written debriefing form.

\section{Results and Discussion}

As in Experiment 1, the participants were allowed to skip any questions they did not feel comfortable answering. There were 5 participants who excluded more than 1 question, but each of these completed at least 15 of the 20 requested. Means, standard deviations, and the results of matched-samples $t$ tests for each memory property for each emotion are shown in Table 5. There were no significant differences between happy and angry memories in intensity or in memory age. There was, predictably, a significant difference in valence between the two, with angry memories being rated as negative and happy memories as positive. When compared with the overall positive-negative differences in Experiment 1, these results are remarkably consistent even though there is more variability in Table 1, due to averaging across many different emotions. Positive memories were more recent than negative memories in Experiment 1, but there was no difference between happy and angry memories here. All significant differences between happy and angry

Table 5

Mean Values (With Standard Deviations) for Happy and Angry Memories Across All Individuals

\begin{tabular}{lcccccc}
\hline & \multicolumn{2}{c}{ Happy } & & \multicolumn{2}{c}{ Angry } & \\
\cline { 2 - 3 } \cline { 5 - 6 } & $M$ & $S D$ & & $M$ & $S D$ & $t(77)$ \\
\hline Recollection & 4.79 & 0.84 & & 4.33 & 0.93 & $5.81^{* *}$ \\
Remember/know & 5.55 & 0.82 & & 5.30 & 0.87 & $3.26^{* *}$ \\
Real/imagine & 5.93 & 0.73 & & 5.74 & 0.81 & $3.01^{* *}$ \\
Vivid & 5.23 & 0.70 & & 4.90 & 0.81 & $4.94^{* *}$ \\
Field/observer & 5.31 & 1.00 & & 5.15 & 1.05 & $2.33^{*}$ \\
In words & 3.33 & 1.24 & & 3.65 & 1.26 & $-4.09^{* *}$ \\
Narrative & 4.36 & 0.82 & & 4.15 & 0.98 & $2.59^{*}$ \\
Specific & 5.68 & 1.00 & & 5.70 & 1.03 & -0.41 \\
Rehearsal & 3.40 & 0.88 & & 3.15 & 0.83 & $3.25^{* *}$ \\
Same intensity & 3.99 & 0.96 & & 3.63 & 1.02 & $3.85^{* *}$ \\
Same emotion & 4.74 & 0.85 & & 4.37 & 0.91 & $4.05^{* *}$ \\
Visceral & 1.57 & 0.60 & & 1.99 & 0.88 & $-5.88^{* *}$ \\
Intensity & 3.73 & 1.03 & & 3.63 & 1.12 & 1.06 \\
Valence & 6.34 & 0.45 & & 2.14 & 0.58 & $44.25^{* *}$ \\
Memory age & 2.99 & 1.51 & & 2.85 & 1.40 & -0.88 \\
\hline
\end{tabular}

Note-Valence is only the positive scale for happy and only the negative scale for angry. $T$ test for valence calculated for positive scale $+(8-$ negative) $/ 2 . N=78 . \quad * p<.05 . \quad * * p<.01$. memories were in the same direction as the differences between positive and negative memories.

Table 6 shows the results of multiple regression analyses conducted on happy and angry memories individually, with memory age, intensity, and valence as predictor variables. Separate regressions were calculated for happy and angry memories so that the positive scale could be used as the valence measure for happy memories and the negative scale for angry memories. As in Experiment 1 , intensity significantly predicted more properties across emotions. The age of the memory failed to significantly predict any AMQ property for either emotion. Valence significantly predicted only recollection and same intensity for happy memories, uniquely accounting for $5 \%$ of the variance or less in each case.

The individual analyses of happiest and angriest memories (again using memory age, intensity, and the individual valence scales) from Experiment 1 are also shown in Table 6. Because these regressions included only one memory per participant, the properties of the memory and individual differences between participants were confounded. The analyses in Experiment 2 resulted in fewer overall significant effects, but of these, only two were not produced by intensity.

In general, the findings in Experiment 1 were extended from individual emotions from positive and negative emotion categories to multiple memories from individual positive and negative emotions. Mean differences between positive and negative memories in Experiment 1 were consistent with those between happy and angry memories. In addition, intensity significantly predicted more autobiographical memory properties than did the age of the memory or the valence for both happy and angry memories individually, just as it did for all the emotions in Experiment 1.

\section{EXPERIMENT 3}

As in Experiment 2, the participants generated multiple autobiographical memories from emotional categories of equal valence but opposite intensity — calm and excited. These emotions have often been used as endpoints on the arousal dimension, and the participants had no difficulty generating multiple memories of each. We again wanted to verify that the effects seen were consistent across various examples of emotional experience and to examine within-subjects effects.

\section{Method}

Participants. Duke University undergraduates $(N=78,24$ of whom were males and none of whom had participated in either Experiment 1 or 2) participated for course credit.

Procedure. The procedure here was the same as that in Experiment 2, with the exception that the participants generated memories of calm events with all 10 individuals before providing excited memories for all 10. This change from the procedure used in Experiment 2 was made because preliminary testing showed that the participants had more difficulty switching between intensity levels than they had had for switching between valences. 
Table 6

Memory Age, Intensity, and Valence (Positive for Happy and Negative for Angry) Regressed on Each of the Autobiographical Memory Properties

\begin{tabular}{|c|c|c|c|c|c|c|c|c|}
\hline & \multicolumn{4}{|c|}{ Experiment 2} & \multicolumn{4}{|c|}{ Experiment 1} \\
\hline & $R^{2}$ & $\beta_{\text {age }}$ & $\beta_{\text {int }}$ & $\beta_{\text {val }}$ & $R^{2}$ & $\beta_{\text {age }}$ & $\beta_{\text {int }}$ & $\beta_{\mathrm{val}}$ \\
\hline \multicolumn{9}{|c|}{ Happy } \\
\hline Recollection & .23 & .03 & $.32 * *$ & $.24 *$ & .37 & -.16 & $.55 * *$ & .03 \\
\hline Remember/know & .09 & -.18 & .16 & .12 & .19 & -.17 & $.29 *$ & .13 \\
\hline Real/imagine & .05 & -.06 & -.05 & .23 & .29 & $-.24 *$ & $.30 *$ & .20 \\
\hline Vivid & .06 & -.08 & .12 & .16 & .40 & $-.26^{* *}$ & $.52 * *$ & .04 \\
\hline Field/observer & .03 & -.15 & -.03 & .14 & .15 & -.15 & $.33 *$ & -.01 \\
\hline In words & .06 & -.06 & .19 & .09 & .08 & -.20 & .12 & .07 \\
\hline Narrative & .03 & -.14 & .04 & .09 & .23 & -.21 & $.33 *$ & .11 \\
\hline Specific & .02 & -.13 & -.04 & .01 & .30 & .14 & $.35 * *$ & $.28 *$ \\
\hline Rehearsal & .18 & -.09 & $.39 * *$ & .05 & .23 & -.13 & $.47 * *$ & -.05 \\
\hline Same emotion & .50 & -.08 & $.63 * *$ & .13 & .34 & $-.24 *$ & $.46^{* *}$ & .06 \\
\hline Same intensity & .43 & -.10 & $.49 * *$ & $.26^{*}$ & .58 & -.07 & $.76^{* *}$ & -.02 \\
\hline Visceral & .13 & -.02 & $.36^{* *}$ & .00 & .22 & -.03 & $.48 * *$ & -.05 \\
\hline \multicolumn{9}{|c|}{ Angry } \\
\hline Recollection & .30 & -.03 & $.52 * *$ & .03 & .26 & -.15 & $.48 * *$ & .03 \\
\hline Remember/know & .08 & -.01 & $.33^{*}$ & -.08 & .23 & $-.27 *$ & $.34 *$ & .12 \\
\hline Real/imagine & .03 & -.15 & -.01 & .12 & .26 & $-.46^{* *}$ & .11 & .19 \\
\hline Vivid & .12 & -.06 & $.35^{*}$ & -.05 & .15 & .00 & $.32 *$ & .10 \\
\hline Field/observer & .02 & -.03 & .10 & .03 & .09 & -.04 & .06 & .26 \\
\hline In words & .14 & .08 & $.48 * *$ & -.24 & .14 & .02 & $.35 *$ & .05 \\
\hline Narrative & .07 & -.15 & .23 & -.12 & .15 & -.22 & $.28 *$ & .07 \\
\hline Specific & .07 & -.13 & .26 & -.16 & .13 & .14 & $.29 *$ & .07 \\
\hline Rehearsal & .23 & .10 & $.49 * *$ & -.01 & .22 & -.14 & $.44 * *$ & .04 \\
\hline Same emotion & .63 & -.07 & $.79 * *$ & .03 & .45 & $-.34 * *$ & $.63 * *$ & .05 \\
\hline Same intensity & .56 & -.08 & $.65^{* *}$ & .12 & .60 & $-.31 * *$ & $.76 * *$ & -.05 \\
\hline Visceral & .37 & -.01 & $.63 * *$ & -.04 & .27 & -.08 & $.55 * *$ & -.06 \\
\hline
\end{tabular}

\section{Results and Discussion}

In this experiment, no participant left more than one emotional memory request blank. A matched-samples $t$ test between each participant's average calm and excited memories revealed no significant difference on the positive scale (see Table 7 for all means, standard deviations, and matched-samples $t$ tests). There was, as was expected, a significant difference for intensity. In addition, there was a significant difference in the ages of the memory, with calm memories being more recent than excited memories. As was seen above, the differences between excited and calm memories parallel the differences between high- and low-intensity emotions shown in Experiment 1. Most of the differences were in the same direction, even if the differences failed to reach significance in one experiment or the other. The only contradiction was that high-intensity memories were significantly more specific than low-intensity memories, whereas calm memories tended to be more specific than excited memories, although this difference was not significant in Experiment 3.

The difference in retention made the inclusion of the age of the memory as a predictor variable (with valence and intensity) in the multiple regression analysis more important here than in the previous experiments. In these analyses (with data from both Experiments 1 and 3), be- cause all the memories were positive, only the positive rating scale was used as the valence measure. As was done previously, Table 8 includes the results of multiple regression analyses from Experiment 3 and the individual analyses of the most excited and the most calm memories from Experiment 1. As was seen in Experiment 2, the effects of intensity were more robust in the individual emotion analyses from Experiment 1, but the overall pattern was consistent.

Memory age significantly predicted a number of autobiographical memory properties for excited memories, with older memories predicting higher ratings in each case. For calm memories, more recent memories were less likely to come in words. However, in no case did the age of the memory uniquely account for more than $12 \%$ of the variance. Valence significantly predicted a number of properties for calm memories, as well as the three emotion-specific properties for excited memories. Just as with memory age, valence never uniquely accounted for more than $12 \%$ of the variance. Across the two emotions, intensity significantly predicted as many autobiographical memory properties as did memory age and valence combined. Although memory age and valence were better predictors of memory properties here than in Experiments 1 and 2, intensity still had greater and more consistent effects. 
Table 7

Mean Values (With Standard Deviations) for Excited and Calm Memories Across All Individuals

\begin{tabular}{lcccccc}
\hline & \multicolumn{2}{c}{ Excited } & & \multicolumn{2}{c}{ Calm } & \\
\cline { 2 - 3 } \cline { 5 - 6 } & $M$ & $S D$ & & $M$ & $S D$ & $t(77)$ \\
\hline Recollection & 4.94 & 1.17 & & 4.49 & 1.17 & $7.44^{* *}$ \\
Remember/know & 5.72 & 0.99 & & 5.61 & 0.92 & 1.84 \\
Real/imagine & 6.06 & 0.79 & & 6.00 & 0.79 & 1.03 \\
Vivid & 5.36 & 0.89 & & 5.22 & 0.78 & $2.26^{*}$ \\
Field/observer & 5.33 & 1.23 & & 5.10 & 1.28 & $2.94^{* *}$ \\
In words & 3.21 & 1.47 & & 3.09 & 1.32 & 1.50 \\
Narrative & 4.72 & 0.96 & & 4.22 & 0.93 & $7.28^{* *}$ \\
Specific & 5.79 & 1.14 & & 5.80 & 1.00 & -0.19 \\
Rehearsal & 3.40 & 0.88 & & 2.70 & 0.78 & $7.85^{* *}$ \\
Same intensity & 3.81 & 1.23 & & 3.05 & 1.04 & $3.27^{* *}$ \\
Same emotion & 4.62 & 0.97 & & 4.36 & 0.84 & $3.72^{* *}$ \\
Visceral & 2.02 & 0.82 & & 1.38 & 0.60 & $7.52^{* *}$ \\
Intensity & 3.80 & 1.25 & & 2.89 & 1.16 & $8.49^{* *}$ \\
Valence & 5.08 & 1.32 & & 5.27 & 0.98 & -1.17 \\
Memory age & 2.28 & 1.43 & & 1.87 & 1.46 & $2.98^{* *}$ \\
\hline
\end{tabular}

Note-Valence is positive scale only for both emotions. $N=78 . \quad{ }^{*} p<$ .05 . $* * p<.01$

In general, the findings in Experiment 1 were extended from individual emotions from high- and low-intensity emotion categories to multiple memories from individual high- and low-intensity emotions, with mean differences between high- and low-intensity memories in Experiment 1 consistent with those between excited and calm memories. Likewise, as in Experiments 1 and 2, intensity significantly predicted more autobiographical memory properties than did the age of the memory or valence.

\section{GENERAL DISCUSSION}

Our results indicate that intensity affects the properties of autobiographical memories more so than does valence. These intensity differences are not the result of a simple retention difference, because the age of the memory was also included in the analyses and it was less influential than intensity or valence. Previous studies have focused on retrieval speed (e.g., Baxter, Yamada, \& Washburn, 1917; Lishman, 1974; Master, Lishman, \& Smith, 1983; Robinson, 1980), the number of positive and negative memories generated (e.g., Henderson, 1911; Jersild, 1931; Meltzer, 1930), or the rate at which memories of opposite valence are forgotten (e.g., Seidlitz, Wyer, \& Diener, 1997; Wohlgemuth, 1923). This study provides a more complex picture of the influence of emotional intensity on memory properties, above and beyond a role in memory accessibility, that is consistent with but expands upon earlier findings. Because we accounted for retention differences in our analyses, the benefits of intensity on phenomenology are in addition to any previously identified benefits in retention. Therefore, not only will highly intense events tend to be remembered longer, but they will also tend to be remembered with greater vividness, a greater sense of recollection, and so forth.

This also implies that even if emotional influence is not of primary interest to an investigator, because intensity is a better predictor of vividness and other properties than is the age of the memory, investigators may do well to cue participants for emotionally intense memories rather than (or in addition to) recent memories. In this way, participant memories are more likely to begin with, for example, high levels of vividness that can then be manipulated by the experimenter to investigate the effects of something other than emotionality on memory phenomenology.

The minimal influence of intensity on a person's belief in the memory's accuracy is unexpected, given the flashbulb memory literature. Flashbulb memories are usually recalled with a higher degree of confidence than other memories of equal age (Brown \& Kulik, 1977; Talarico \& Rubin, 2003), even when individuals are confronted with evidence that the event in memory could not have occurred as it is remembered (Neisser \& Harsch, 1992). The most common explanation for such persistent, confident recall is that the memory event was highly intense and negative in valence. This evidence suggests that it may be other features of the flashbulb memory event that lead to such confident recall-perhaps increased rehearsal or the desire to incorporate oneself into a larger historical context.

Intensity had more consistent and larger effects than did valence in our three experiments, with the effects of intensity influencing a large and diverse group of autobiographical memory properties. This is consistent with the literature reviewed earlier, which tended to investigate similar properties individually. Why should this be the case? One possibility is that emotions may be unique in many ways but that their effects on memory operate through factors that are mediated most strongly by intensity. For instance, emotional intensity may serve to enhance attentional mechanisms at encoding, so that all features of the event benefit at recall. Alternatively, the vector model that characterizes emotions in terms of intensity (once a dichotomous choice has been made about valence) may be the best way to consider the effects of emotion on memory.

The robust effect of intensity has been conceded even by those who have argued for valence effects in retention and/or accessibility. Matlin and Stang (1978) in the context of defining the "Pollyanna principle," a bias toward pleasantness, stated "The Intensity Principle maintains that intense or highly polarized items are processed more efficiently than those which are neutral or unpolarized. ... extremely pleasant or extremely unpleasant items would be processed with equal efficiency, while neutral items would be processed more slowly and less accurately" (p. 12, emphasis in original). The absence of any consistent effects of valence on memory properties is consistent with the relative absence of such effects in recall.

Beyond dissociating the effects of valence and intensity in support of a dimensional view of emotion, the present study also adds autobiographical memories to those stimuli that can be described by a vector model. Asking participants to generate autobiographical memories of different types of emotional experience and then plotting the self-rated valence and intensity of each would 
Table 8

Memory Age, Intensity, and Valence (Positive Only) Regressed on Each of the Autobiographical Memory Properties

\begin{tabular}{|c|c|c|c|c|c|c|c|c|}
\hline & \multicolumn{4}{|c|}{ Experiment 3} & \multicolumn{4}{|c|}{ Experiment 1} \\
\hline & $R^{2}$ & $\beta_{\text {age }}$ & $\beta_{\text {int }}$ & $\beta_{\mathrm{val}}$ & $R^{2}$ & $\beta_{\text {age }}$ & $\beta_{\text {int }}$ & $\beta_{\mathrm{val}}$ \\
\hline \multicolumn{9}{|c|}{ Excited } \\
\hline Recollection & .27 & $-.28 *$ & $.43 * *$ & .00 & .28 & -.20 & $.47 * *$ & -.11 \\
\hline Remember/know & .14 & $-.28 *$ & .17 & .09 & .33 & -.06 & $.52 * *$ & .04 \\
\hline Real/imagine & .10 & -.09 & .18 & .19 & .10 & -.18 & .11 & .11 \\
\hline Vivid & .33 & $-.33 * *$ & $.49 * *$ & -.10 & .35 & -.16 & $.49 * *$ & .04 \\
\hline Field/observer & .21 & $-.36 * *$ & $.32 * *$ & -.14 & .13 & -.19 & .18 & .09 \\
\hline In words & .24 & $-.25^{*}$ & $.44 * *$ & -.19 & .11 & -.03 & $.36^{*}$ & -.10 \\
\hline Narrative & .23 & $-.27^{*}$ & $.41 * *$ & -.11 & .33 & $-.32 * *$ & $.25^{*}$ & .18 \\
\hline Specific & .01 & -.05 & .10 & -.05 & .07 & .07 & .22 & .10 \\
\hline Rehearsal & .20 & $-.27^{*}$ & $.37 * *$ & -.03 & .36 & .00 & $.63 * *$ & -.07 \\
\hline Same emotion & .63 & -.04 & $.74 * *$ & $.17^{*}$ & .41 & $-.23^{*}$ & $.44 * *$ & .12 \\
\hline Same intensity & .51 & -.12 & $.62 * *$ & $.22 *$ & .50 & $-.20 *$ & $.63 * *$ & -.05 \\
\hline Visceral & .33 & -.05 & $.56 * *$ & $-.22^{*}$ & .33 & .00 & $.65^{* *}$ & -.20 \\
\hline \multicolumn{9}{|c|}{ Calm } \\
\hline Recollection & .10 & -.12 & $.26 * *$ & .14 & .34 & -.04 & $.52 * *$ & .14 \\
\hline Remember/know & .07 & .03 & -.01 & $.26^{*}$ & .29 & -.02 & $.45 * *$ & .17 \\
\hline Real/imagine & .05 & .08 & .15 & .13 & .24 & -.09 & $.29 *$ & $.30 *$ \\
\hline Vivid & .23 & .01 & $.31 * *$ & $.32 * *$ & .25 & .03 & $.49 * *$ & .04 \\
\hline Field/observer & .10 & -.15 & .17 & .19 & .14 & -.16 & .23 & .15 \\
\hline In words & .35 & $-.29 * *$ & $.54 * *$ & .06 & .24 & .03 & $.52 * *$ & -.21 \\
\hline Narrative & .17 & .03 & $.30 * *$ & $.25 *$ & .20 & -.03 & $.43 * *$ & .02 \\
\hline Specific & .06 & .14 & -.03 & .22 & .09 & -.07 & .08 & $.26^{*}$ \\
\hline Rehearsal & .24 & -.01 & $.49 * *$ & -.02 & .35 & -.09 & $.52 * *$ & .11 \\
\hline Same emotion & .49 & -.04 & $.66^{* *}$ & .16 & .48 & -.08 & $.59 * *$ & $.20 *$ \\
\hline Same intensity & .26 & -.17 & $.38 * *$ & $.26^{*}$ & .65 & .05 & $.76 * *$ & .15 \\
\hline Visceral & .40 & .01 & $.60 * *$ & $-.22 * *$ & .27 & .12 & $.53 * *$ & $-.29 *$ \\
\hline
\end{tabular}

Note-For Experiment 3, $N=78$ for both excited and calm. For Experiment 1, $N=69$ for excited, $N=70$ for calm. $\quad * p<.05 . \quad * * p<.01$.

further test whether the vector model does adequately describe autobiographical memory patterns or whether the circumplex can be supported with additional data. In particular, examples of low-intensity emotions need to be better represented. At this time, the vector model appears more promising.

The primary benefit of the present approach is the simultaneous examination of many autobiographical memory properties. The majority of these are influenced primarily by emotional intensity. With this framework, better targeted research of each individual property is possible. New research on linguistic properties or recollection as influenced by intensity is recommended, as is more focused research on how, when, and in what manner intensity operates to enhance these and other autobiographical memory properties. In addition to extending our general understanding of autobiographical memory and how it is influenced by emotion, such investigations could inform research on emotional memory disorders, such as posttraumatic stress disorder (Berntsen et al., 2003; Rubin et al., 2004), over-general autobiographical memories in depression, or enhanced memory for threatening material in patients with anxiety disorders (Wenzel, Pinna, \& Rubin, 2004). Expanding research on the interaction and integration of emotion and autobiographical memory can only improve our understanding of each individually.

\section{REFERENCES}

Anderson, S. J., Cohen, G., \& TAYlor, S. (2000). Rewriting the past: Some factors affecting the variability of personal memories. Applied Cognitive Psychology, 14, 435-454.

ANISFELD, M., \& LAMBERT, W. E. (1966). When are pleasant words learned faster than unpleasant words? Journal of Verbal Learning \& Verbal Behavior, 5, 132-141.

BANAJI, M. R., \& HARDIN, C. (1994). Affect and memory in retrospective reports. In N. Schwarz \& S. Sudman (Eds.), Autobiographical memory and the validity of retrospective reports (pp. 71-86). New York: Springer-Verlag.

BARLOW, J. A. (1955). Recall of experiences as a function of intensity as compared to quality (pleasantness or unpleasantness) of feeling tone. Journal of the Scientific Laboratories, 43, Arts, pp. 9-12.

Baumeister, R. F., Bratslavsky, E., Finkenauer, C., \& Vohs, K. D. (2001). Bad is stronger than good. Review of General Psychology, 5, 323-370.

BAXTER, M. F., YAmada, K., \& Washburn, M. F. (1917). Minor studies from the psychological laboratory of Vassar College: Directed recall of pleasant and unpleasant experiences. American Journal of Psychology, 28, 155-157.

BeRntSEn, D. (1996). Involuntary autobiographical memories. Applied Cognitive Psychology, 10, 435-454.

BERNTSEN, D. (1998). Voluntary and involuntary access to autobiographical memory. Memory, 6, 113-141.

BERNTSEN, D. (2001). Involuntary memories of emotional events: Do memories of traumas and extremely happy events differ? Applied Cognitive Psychology, 15, S135-S158.

BernTSEN, D., \& RuBIN, D. C. (2002). Emotionally charged autobiographical memories across the lifespan: The retention of happy, sad, 
traumatic, and involuntary memories. Psychology \& Aging, 17, 636652.

Berntsen, D., Willert, M., \& Rubin, D. C. (2003). Splintered memories or vivid landmarks? Recollective qualities and organization of traumatic memories in PTSD. Applied Cognitive Psychology, 17, 675-693.

BLUCK, S., \& LI, K. Z. H. (2001). Predicting memory completeness and accuracy: Emotion and exposure in repeated autobiographical recall. Applied Cognitive Psychology, 15, 145-158.

Bradley, M. M., Codispoti, M., Cuthbert, B. N., \& Lang, P. J. (2001). Emotion and motivation: I. Defensive and appetitive reactions in picture processing. Emotion, 1, 276-298.

Bradley, M. M., Greenwald, M. K., Petry, M. C., \& Lang, P. J. (1992). Remembering pictures: Pleasure and arousal in memory. Journal of Experimental Psychology: Learning, Memory, \& Cognition, 18, 379-390.

BRADLEY, M. M., \& LANG, P. J. (1999). Affective norms for English words $(A N E W)$ : Instruction manual and affective ratings (Tech. Rep. C-1). Gainesville: University of Florida, Center for Research in Psychophysiology.

Brewer, W. F. (1986). What is autobiographical memory? In D. C. Rubin (Ed.), Autobiographical memory (pp. 25-49). New York: Cambridge University Press.

BREWER, W. F. (1995). What is recollective memory? In D. C. Rubin (Ed.), Remembering our past: Studies in autobiographical memory (pp. 19-66). New York: Cambridge University Press.

Brown, R., \& Kulik, J. (1977). Flashbulb memories. Cognition, 5, 7399.

CARTER, H. D. (1936). Emotional correlates of errors in learning. Journal of Educational Psychology, 27, 55-67.

Carter, H. D., Jones, H. E., \& SHock, N. W. (1934). An experimental study of affective factors in learning. Journal of Educational Psychology, 25, 203-215.

CAson, H. (1932). The learning and retention of pleasant and unpleasant activities. Archives of Psychology, 134, 1-96.

Christianson, S.-Å. (1992a). Do flashbulb memories differ from other types of emotional memories? In E. Winograd \& U. Neisser (Eds.), Affect and accuracy in recall: Studies of "flashbulb" memories (Vol. 4, pp. 191-211). New York: Cambridge University Press.

Christianson, S.-Å. (1992b). Emotional stress and eyewitness memory: A critical review. Psychological Bulletin, 112, 284-309.

Clark, H. H. (1973). The language-as-fixed-effect fallacy: A critique of language statistics in psychological research. Journal of Verbal Learning \& Verbal Behavior, 12, 335-359.

Conte, H. R., \& PlutchiK, R. (1981). A circumplex model for interpersonal personality traits. Journal of Personality \& Social Psychology, 40, 701-711.

CoNWAY, M. A. (1990). Conceptual representation of emotions: The role of autobiographical memories. In K. J. Gilhooly, M. T. G. Keane, R. H. Logie, \& G. Erdos (Eds.), Lines of thinking: Reflections on the psychology of thought: Vol. 2. Skills, emotion, creative processes, individual differences and teaching thinking (pp. 133-143). Oxford: Wiley.

Conway, M. A., \& Bekerian, D. A. (1987a). Organization in autobiographical memory. Memory \& Cognition, 15, 119-132.

Conway, M. A., \& BEKERIAN, D. A. (1987b). Situational knowledge and emotions. Cognition \& Emotion, 1, 145-191.

CONWAY, M. A., \& BeKerian, D. A. (1988). Characteristics of vivid memories. In R. N. Sykes (Ed.), Practical aspects of memory: Current research and issues. Vol. 1: Memory in everyday life (pp. 519524). New York: Wiley.

D'Argembeau, A., Comblain, C., \& Van Der Linden, M. (2003). Phenomenal characteristics of autobiographical memories for positive, negative, and neutral events. Applied Cognitive Psychology, 17, 281-294.

Destun, L. M., \& KuiPer, N. A. (1999). Phenomenal characteristics associated with real and imagined events: The effects of event valence and absorption. Applied Cognitive Psychology, 13, 175-186.
Duffy, E. (1934). Emotion: An example of the need for reorientation in psychology. Psychological Review, 41, 184-198.

DufFY, E. (1941). An explanation of "emotional" phenomena without the use of the concept "emotion." Journal of General Psychology, 25, 283-293.

Dunlap, K. (1932). Are emotions teleological constructs? American Journal of Psychology, 44, 572-576.

EKMAN, P. (1992). Are there basic emotions? Psychological Review, 99, 550-553.

Fisher, G. A., Heise, D. R., Bohrnstedt, G. W., \& LucKe, J. F. (1985). Evidence for extending the circumplex model of personality trait language to self-reported moods. Journal of Personality \& Social Psychology, 49, 233-242.

Gordon, K. (1928). A study of early memories. Journal of Delinquency, 12, 129-132.

GuY, S. C., \& CAHILl, L. (1999). The role of overt rehearsal in enhanced conscious memory for emotional events. Consciousness \& Cognition, 8, 114-122.

Hayes, P., Conway, M. A., \& Morris, P. E. (1992). Evaluating "the cognitive structure of emotions" using autobiographical memories of emotional events. In M. A. Conway, D. C. Rubin, H. Spinnler, \& W. A. Wagenaar (Eds.), Theoretical perspectives on autobiographical memory (pp. 353-374). Boston: Kluwer.

HENDERSON, E. N. (1911). Do we forget the disagreeable? Journal of Philosophy, Psychology \& Scientific Methods, 8, 432-437.

Holmes, D. S. (1970). Differential change in affective intensity and the forgetting of unpleasant personal experiences. Journal of Personality \& Social Psychology, 15, 234-239.

IzARD, C. E. (1992). Basic emotions, relations among emotions, and emotion-cognition relations. Psychological Review, 99, 561-565.

JERSILD, A. (1931). Memory for the pleasant as compared with the unpleasant. Journal of Experimental Psychology, 14, 284-288.

LANG, P. J. (1995). The emotion probe: Studies of motivation and attention. American Psychologist, 50, 372-385.

LANG, P. J., BRADLEY, M. M., \& CUTHBERT, B. N. (1999). International affective picture system (IAPS): Instruction manual and affective ratings (Tech. Rep. A-4). Gainesville: University of Florida, Center for Research in Psychophysiology.

LARSEN, S. (1998). What is it like to remember? On phenomenal qualities of memory. In C. P. Thompson, D. J. Herrmann, D. Bruce, J. D. Read, D. G. Payne, \& M. P. Toglia (Eds.), Autobiographical memory: Theoretical and applied perspectives (pp. 163-190). Mahwah, NJ: Erlbaum.

LEVINE, L. J. (1997). Reconstructing memory for emotions. Journal of Experimental Psychology: General, 126, 165-177.

LiNTON, M. (1975). Memory for real-world events. In D. A. Norman \& D. E. Rumelhart (Eds.), Explorations in cognition (pp. 376-404). San Francisco: Freeman.

Lishman, W. A. (1974). The speed of recall of pleasant and unpleasant experiences. Psychological Medicine, 4, 212-218.

Loftus, E. F., Donders, K., Hoffman, H. G., \& Schooler, J. W. (1989). Creating new memories that are quickly accessed and confidently held. Memory \& Cognition, 17, 607-616.

Master, D., Lishman, W. A., \& Smith, A. (1983). Speed of recall in relation to affective tone and intensity of experience. Psychological Medicine, 13, 325-331.

Matlin, M. W., \& Stang, D. J. (1978). The Pollyanna principle: Selectivity in language, memory, and thought. Cambridge, MA: Schenkman.

Meltzer, H. (1930). Individual differences in forgetting pleasant and unpleasant experiences. Journal of Educational Psychology, 21, 399409.

MenziEs, R. (1935). The comparative memory values of pleasant, unpleasant and indifferent experiences. Journal of Experimental Psychology, 18, 267-279.

NeIsser, U. (1981). John Dean's memory: A case study. Cognition, $\mathbf{9}_{2}$ $1-22$.

NEISSER, U., \& HARSCH, N. (1992). Phantom flashbulbs: False recollections of hearing the news about Challenger. In E. Winograd \& 
U. Neisser (Eds.), Affect and accuracy in recall: Studies of "flashbulb" memories (Vol. 4, pp. 9-31). New York: Cambridge University Press.

Nigro, G., \& NeIsser, U. (1983). Point of view in personal memories. Cognitive Psychology, 15, 467-482.

OATLEY, K., \& JOHNSON-LAIRD, P. N. (1987). Towards a cognitive theory of emotions. Cognition \& Emotion, 1, 29-50.

O'KELLY, L. I., \& STECKLE, L. C. (1940). The forgetting of pleasant and unpleasant experiences. American Journal of Psychology, 53, 432434.

Ortony, A., Turner, T. J., \& Antos, S. J. (1983). A puzzle about affect and recognition memory. Journal of Experimental Psychology: Learning, Memory, \& Cognition, 9, 725-729.

OsGood, C. E. (1966). Dimensionality of the semantic space for communication via facial expressions. Scandinavian Journal of Psychology, 7, 1-30.

RASPOTNIG, M. A. (1997). Subcomponents of imagery and their influence on emotional memories. Journal of Mental Imagery, 21, 135146.

Reisberg, D., Heuer, F., McLean, J., \& O’Shaughnessy, M. (1988). The quantity, not the quality, of affect predicts memory vividness. Bulletin of the Psychonomic Society, 26, 100-103.

Robinson, J. A. (1980). Affect and retrieval of personal memories. Motivation \& Emotion, 4, 149-174.

Robinson, J. A., \& Swanson, K. L. (1993). Field and observer modes of remembering. Memory, 1, 169-184.

RuBin, D. C. (1985). Memorability as a measure of processing: A unit analysis of prose and list learning. Journal of Experimental Psychology: General, 114, 213-238.

RUBIN, D. C., \& BERNTSEN, D. (2003). Life scripts help to maintain autobiographical memories of highly positive, but not highly negative, events. Memory \& Cognition, 31, 1-14.

Rubin, D. C., Burt, C. D. B., \& Fifield, S. J. (2003). Experimental manipulations of the phenomenology of memory. Memory \& Cognition, 31, 877-886.

Rubin, D. C., Feldman, M. E., \& Beckham, J. C. (2004). Reliving, emotions, and fragmentation in the autobiographical memories of veterans diagnosed with PTSD. Applied Cognitive Psychology, 1, 17-35.

Rubin, D. C., \& KozIn, M. (1984). Vivid memories. Cognition, 16, 8195.

Rubin, D. C., Schrauf, R. W., \& Greenberg, D. L. (2003). Belief and recollection of autobiographical memories. Memory \& Cognition, 31, 887-901.

RUSSELL, J. A. (1980). A circumplex model of affect. Journal of Personality \& Social Psychology, 39, 1161-1178.

RUSSELL, J. A., \& CARROLL, J. M. (1999). On the bipolarity of positive and negative affect. Psychological Bulletin, 125, 3-30.

Schwartz, G. E., Weinberger, D. A., \& Singer, J. A. (1981). Cardiovascular differentiation of happiness, sadness, anger, and fear following imagery and exercise. Psychosomatic Medicine, 43, 343-364.

Seidlitz, L., JR., Wyer, R. S., \& Diener, E. (1997). Cognitive correlates of subjective well-being: The processing of valenced life events by happy and unhappy persons. Journal of Research in Personality, 31, 240-256.

SHEEN, M., KeMP, S., \& Rubin, D. (2001). Twins dispute memory ownership: A new false memory phenomenon. Memory \& Cognition, 29, $\underline{779-788 .}$
STAGNER, R. (1933). Factors influencing the memory value of words in a series. Journal of Experimental Psychology, 16, 129-137.

Strongman, K. T., \& Kemp, S. (1991). Autobiographical memory for emotion. Bulletin of the Psychonomic Society, 29, 195-198.

Talarico, J., \& Rubin, D. C. (2003). Confidence, not consistency, characterizes flashbulb memories. Psychological Science, 14, 455-461.

THOMPson, C. P. (1985). Memory for unique personal events: Effects of pleasantness. Motivation \& Emotion, 9, 277-289.

Tromp, S., Koss, M. P., Figueredo, A. J., \& Tharan, M. (1995). Are rape memories different? A comparison of rape, other unpleasant, and pleasant memories among employed women. Journal of Traumatic Stress, 8, 607-627.

VAN DER KOLK, B. A., \& FISLER, R. (1995). Dissociation and the fragmentary nature of traumatic memories: Overview and exploratory study. Journal of Traumatic Stress, 8, 505-525.

WAgenaAR, W. A. (1986). My memory: A study of autobiographical memory over six years. Cognitive Psychology, 18, 225-252.

Walker, W. R., Vogl, R. J., \& Thompson, C. P. (1997). Autobiographical memory: Unpleasantness fades faster than pleasantness over time. Applied Cognitive Psychology, 11, 399-413.

Washburn, M. F., DeYo, D., \& Marks, D. (1924). A further study of revived emotions. American Journal of Psychology, 35, 113-120.

Washburn, M. F., Field, R., \& Wolf, E. D. (1923). A study of revived emotions. American Journal of Psychology, 34, 99-103.

Washburn, M. F., Giang, F., Ives, M., \& Pollock, M. (1925). Memory revival of emotions as a test of emotional and phlegmatic temperaments. American Journal of Psychology, 36, 456-459.

WAters, R. H., \& LeEPER, R. (1936). The relation of affective tone to the retention of experiences of daily life. Journal of Experimental Psychology, 19, 203-215.

Wenzel, A., Pinna, K., \& Rubin, D. C. (2004). Autobiographical memories of anxiety-related experiences. Behaviour Research \& Therapy, 42, 329-341.

WHITE, R. T. (1982). Memory for personal events. Human Learning, 1, 171-183.

White, R. [T.] (2002). Memory for events after twenty years. Applied Cognitive Psychology, 16, 603-612.

Williams, J. M. G. (1995). Depression and the specificity of autobiographical memory. In D. C. Rubin (Ed.), Remembering our past: Studies in autobiographical memory (pp. 244-267). Cambridge: Cambridge University Press.

Wohlgemuth, A. (1923). The influence of feeling on memory. British Journal of Psychology, 13, 405-416.

\section{NOTE}

1. Due to concerns that this phrasing may have biased our results toward intensity, we had 37 new participants follow the same procedure, but with all potentially biasing phrases removed (e.g., "especially" and "extremely"). The results from that experiment were not remarkably different from those shown for Experiment 1 here. There were still more significant differences between high- and low-intensity emotions than between positive and negative emotions, and intensity was still a significant predictor of more autobiographical memory properties than was valence or the age of the memory. We are therefore confident that our results were not the product of implicit demand characteristics. More information is available from the authors upon request. 
Please think about a specific event when you felt especially HAPPY. Think about that memory for a minute or so until you have a sense of completion, that you have indeed remembered the event in its entirety and to its full intensity.

Please write a brief, 2-3 word description of this memory, which need be intelligible only to you, that is specific enough to remind you of that unique memory at a later time.

1. While remembering the event, I feel as though I am reliving it.

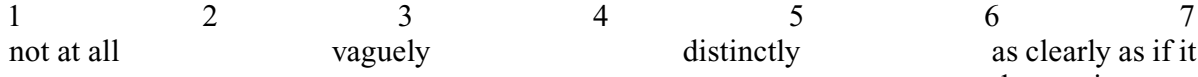

$$
\begin{aligned}
& \text { were happening now }
\end{aligned}
$$

2. While remembering the event, it comes to me in words or in pictures as a coherent story or episode and not as an isolated fact, observation, or scene.
1
3
4
5
6
completely

3. While remembering the event, I feel that I see it out of my own eyes rather than that of an outside observer.
1
3
4
5
6
completely

4. My memory comes in pieces with missing bits.
12
3
4
5
6
completely

5. While remembering the event, I feel the same particular emotions I felt at the time of the event.
1
23
4
5
6
identically the same

6. While remembering the event, I feel the emotions as strongly as I did then.
1
3
vaguely
45
distinctly
6
as clearly as if it
were happening now

7. While remembering the event, the emotions are extremely positive.

$\begin{array}{llrrr}1 & 2 & 3 & 4 & 5 \\ \text { not at all } & & \text { hardly } & & \text { somewhat }\end{array}$
hile remembering the event, the emotions are extremely negative.
1
23
4
somewhat

6

entirely

9. The emotions that I feel are extremely intense.

$\begin{array}{llrrrrr}1 & 2 & 3 & 4 & 5 & 6 & 7 \\ \text { not at all } & & \text { hardly } & & \text { somewhat } & & \text { entirely }\end{array}$

10. While remembering the event, I feel my heart pound, or race.
not at all
3
4
5
$6 \quad 7$
more than for any other memory

11. While remembering the event, I feel sweaty or clammy.
12
3
4
5
$6 \quad 7$ other memory
more than for any

12. While remembering the event, I feel tense all over or I feel knots, cramps, or butterflies in my stomach.
12
3
4
5
$6 \quad 7$
not at all
more than for any
other memory

13. While remembering the event, I can see it in my mind.
1
3
4
5
distinctly
6
7
as clearly as if it
were happening now

14. While remembering the event, I can hear it in my mind.
1
2
3
vaguely
45
distinctly
not at all

\section{5}

$6 \quad 7$

as clearly as if it were happening now 
15. While remembering the event, I know the setting where it occurred.

$\begin{array}{lrrrrr}1 & 2 & 3 & 5 & 6 & 7 \\ \text { not at all } & \text { vaguely } & 4 & \text { distinctly } & \text { as clearly as if it } \\ & & & & \text { were happening now }\end{array}$

16. While remembering the event, I feel that I travel back to the time when it happened.
1
2
3
45 distinctly
6 vaguely
completely

17. My memory is based on details specific to my life, not on general knowledge that I would expect most people to have.
1
2
3
45
not at all
in some details
in some main points
$6 \quad 7$
completely

18. While remembering the event, it comes to me in words.
1
vaguely
$4 \quad 5$
distinctly
$6 \quad 7$
completely

19. As I think about the event, I can actually remember it rather than just knowing that it happened.
1
2
3
4
5
not at all
vaguely
distinctly
$6 \quad 7$
completely

20. Since it happened, I have thought or talked about this event.
not at all
sometimes
many times
$6 \quad 7$
more than for any other memory

21. This memory has previously come to me "out of the blue," without my trying to think about it.
1
not at all
3
sometimes
4
many times
6
$\begin{aligned} & 6 \\ & \text { more than for any } \\ & \text { other memory }\end{aligned}$

22. I believe the event in my memory really occurred in the way I remember it and that I have not imagined or fabricated anything that did not occur.
$100 \%$ imaginary
34
4
$5 \quad 6$
$6 \quad 7$
23. How old are you in this memory?
years old

(Manuscript received September 12, 2002;

revision accepted for publication February 9, 2004.) 